\title{
EXPERIMENTAL AND NUMERICAL ANALYSES OF THE IMPACT RESPONSE OF LIGHTWEIGHT SANDWICH PANELS
}

\author{
Oana Mocian, Dan M. Constantinescu, Stefan Sorohan, Marin Sandu
}

University POLITEHNICA of Bucharest, 060042 Bucharest, Romania. E-mails: mocianoana@gmail.com, dan.constantinescu@upb.ro, stefan.sorohan@upb.ro, marin.sandu@upb.ro

\section{Introduction}

Sandwich panels with lightweight different cores are nowadays essential structural components which offer integrity and reliability to ground vehicles and aircrafts. Low speed impacts may result from the collision with roadside safety elements, e.g., guard and bridge rails, median barriers or sign supports, hail or debris thrown up from runaways and even from tools dropped during maintenance. Experimental determination of the impact behavior of sandwich panels is neither resourceful nor cost effective [1-2], and in many cases finite element modeling (FEM) and analysis are used for these types of studies to predict the behavior and failure of these panels, [35]. However, the calibration of the FEM impact model should be carefully done and only experimental results can provide a good understanding of the impact phenomena and response of the sandwich panel in conjunction to the localized damage produced after the lowvelocity impact.

\section{Experimental impact testing}

An instrumented Instron Ceast 9340 Drop Tower Impact System used a striker of $20 \mathrm{~mm}$ diameter and the impact force was measured during the impact. The initial impact velocity of the striker was measured with an optical cell. The sandwich plates of $140 \times 140 \mathrm{~mm}$ were placed on an adjustable in height test specimen support with a circular hole of $100 \mathrm{~mm}$ diameter (Fig. 1), which eventually allowed the striker to fall if the plate was perforated. A clamping ring was pressed over the sandwich plate by a pneumatic system with a maximum force of $3 \mathrm{kN}$. A special attention was given to the positioning and the alignment of the specimen as to obtain the impact in the middle of the plate. Fig. 1 shows the sandwich panel fixed in between the specimen support and the clamping ring. The energy carrier of gravitationally accelerated type had a mass of $3.15 \mathrm{~kg}$ and two additional masses of $5 \mathrm{~kg}$ each were added. Therefore the total mass of the energy carrier was $13.15 \mathrm{~kg}$. The European Standard ISO 6603-2: 2000, "Plastics - Determination of puncture impact behavior of rigid plastics - Part 2: Instrumented impact testing" was used. This standard was last reviewed and confirmed in 2015. Data acquisition was done with a frequency of $200 \mathrm{kHz}$.

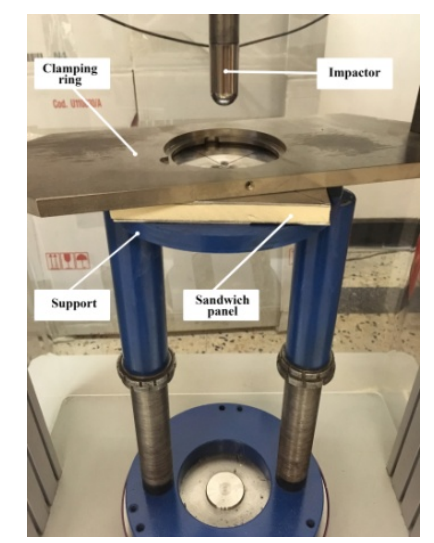

Fig. 1. Impact of sandwich plate during testing.

\section{Description of sandwich panels}

The sandwich panels had skins made of aluminum $\mathrm{Al}$ 6082-T6 of $1.5 \mathrm{~mm}$ thickness glued with Araldite AW106 (Huntsman) to two types of core: polyurethane Necuron 100 of density 100 $\mathrm{kg} / \mathrm{m}^{3}$ and commercial extruded polystyrene of density $30 \mathrm{~kg} / \mathrm{m}^{3}$ having thicknesses of $12 \mathrm{~mm}$, respectively $19 \mathrm{~mm}$. The polyurethane core sandwich was abbreviates as PS_PUR and the polystyrene core sandwich as PS_PE. Although the thickness of the polystyrene core of the PS_PE sandwich is greater than the polyurethane core of the PS_PUR sandwich the average mass of the PS_PE panel is about 186 grams compared to about 199 grams for the PS_PUR panel. So, from the point of view of a lightweight panel, the polystyrene sandwich core stands in fact better. The initial velocity of impact was increased from $0.77 \mathrm{~m} / \mathrm{s}$ up to $3.5 \mathrm{~m} / \mathrm{s}$ (height of impact from 30 $\mathrm{mm}$ up to $625 \mathrm{~mm}$ ), in some cases reaching $4.5 \mathrm{~m} / \mathrm{s}$ for both panels as being the maximum speed considered in these tests. 


\section{Finite element simulations}

The core material was modeled using three different core material models supplied by the LSDyna software: honeycomb, low density and crushable foam material model [5]. Both skins and the core were meshed with one single integration point, eight node solid elements. The mesh was refined in the region of impact in order to better describe the behavior of the plate (Fig. 2). A total number of 16000 elements were used for the skins and 24000 for the core. The impactor, the support and the clamping ring were all modeled as rigid bodies, with the same type of solid elements.

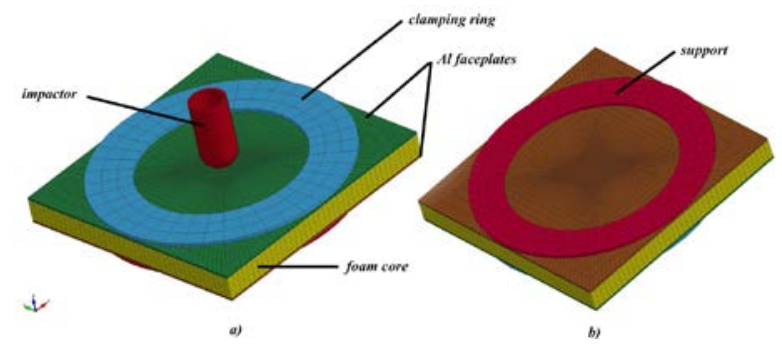

Fig. 1. Finite element model of sandwich plate: a) top view; b) back view.

\section{Comparison of experimental and numerical results}

In the case of a linear elastic impact event the impact force curve variation in time should be symmetric for loading and unloading. This does not happen even for the lower initial speed of impact of $1.5 \mathrm{~m} / \mathrm{s}$ showing that unloading is accompanied by additional damage phenomena. For a polyurethane panel sandwich (PS_PUR) the first impact events take about $9 \mathrm{~ms}$ at $1.5 \mathrm{~m} / \mathrm{s}$ to 13 $\mathrm{ms}$ at $3.5 \mathrm{~m} / \mathrm{s}$. At $3.5 \mathrm{~m} / \mathrm{s}$, as seen in Fig. 3, the force drops suddenly from $11790 \mathrm{~N}$ to $4450 \mathrm{~N}$ due to the severe damage of the aluminum top face of the sandwich which is penetrated by the striker.

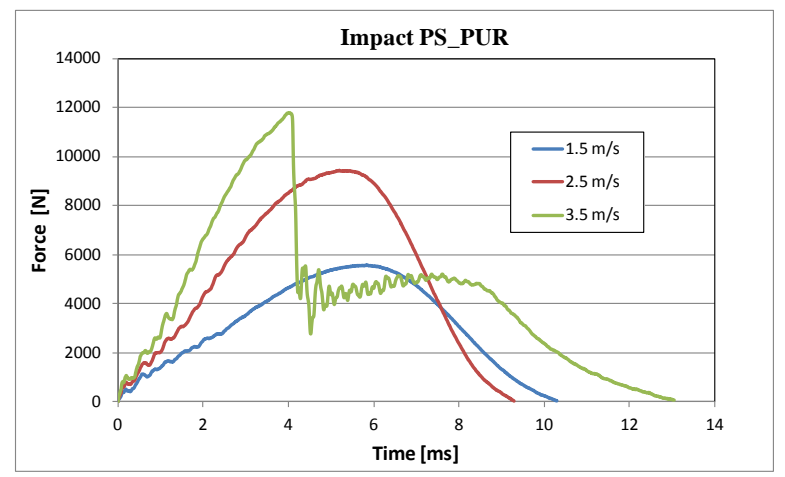

Fig. 3. Impact response of the PS_PUR at three speeds of impact.

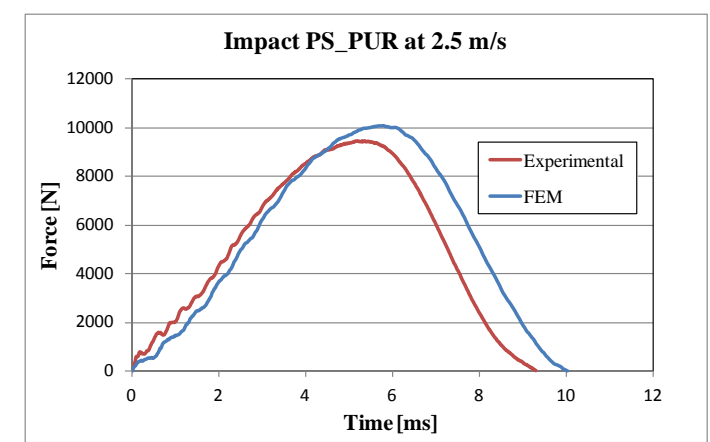

Fig. 4. Comparison of experimental and FEM force-time response of PS_PUR.

At $2.5 \mathrm{~m} / \mathrm{s}$ the response of the polyurethane sandwich panel is compared in Fig. 4 as resulting from the experiment and FEM simulation, considering a honeycomb material model for the core. The agreement is good.

\section{Acknowledgements}

Miss Oana Mocian acknowledges the $\mathrm{PhD}$ student scholarship given by the Ministry of National Education from Romania through the contract no. 06.40/2014 which made possible the present researches.

\section{References}

[1] Wang, J., Waas, A.M., Wang, H., Experimental and numerical study on the low velocity impact behavior of foam-core sandwich panels, Compos. Struct., 96, 2013, pp. 298-311.

[2] Caliskan, U., Apalak, M.K., Low velocity impact behavior of foam core sandwich beams: Experimental, Compos. Part B-Eng., 112, 2017, pp. 158-175.

[3] Hazizan, M.A., Cantwell, W.J., The low velocity impact response of foam-based sandwich structures, Compos. Part B-Eng., 33, 2002, pp. 193-204.

[4] Chang, F.S., Hallquist, J.O., Lu, D.X., Shahidi, B.K., Kudelko, C.M., Tekelly, J.P., Finite Element Analysis of Low-Density High-Hysteresis Foam Materials and the Application in the Automotive Industry, SAE Paper 940908, SAE International Congress and Exposition, Detroit, February 1994, pp. 71-78.

[5] Croop, B., Lobo, H., Selecting Material Models for the Simulation of Foams in LSDYNA, 7th European LS-DYNA Conference, Salzburg, Austria, May, 2009. 